\title{
ACUTE LEUKAEMIAS ON BONE MARROW EXAMINATION AND CLINICAL MANIFESTATIONS IN THE TELANGANA POPULATION
}

\section{S. Praveena *1, K. Durga 2 .}

${ }^{* 1}$ Assistant professor, Pathology Department, Dr. Patnam Mahender reddy institute of medical sciences, Hyderabad, Telangana, India.

${ }^{2}$ Professor of Pathology, Osmania M edical College, Hyderabad, Telangana, India.

\section{ABSTRACT}

These lymphoid and myeloid leukemias are associated with varied systemic involvement such as anemia, splenomegaly, generalized lymphadenopathy and petechial haemorrhagic spots. For this reason, the clinician also requires the basic peripheral blood smear study as a preliminary examination to differentiate the various diseases that overlap the symptomatology of acute leukemia clinically. With this background we examined bone marrow and clinical manifestations for rule out the acute leukaemias in Telangana population. During the 25 months of study a total of 36 cases of leukaemias were studied in the Department of pathology, Kakatiya Medical College, Warangal in collaboration with Lifeline Diagnostics, Hyderabad. Out of 36 cases, 20 cases were AM L, 15 cases were ALL and 1 case was mixed phenotypic acute leukaemia. The highest number of cases in the adults belonged to AM L (16 cases). In children ALL (13cases) formed the majority of cases followed by AM L (4 cases). The most common presentation in the study population followed by splenomegaly (38.8\%). Out of the AM L cases studied, 13 cases were diagnosed by morphology alone and in 5 cases, cytogenetic study helped in sub typing the cases. Out of the ALL cases studied 5 cases were diagnosed by morphology alone and in 3 Cases, cytogenetic studies confirmed the diagnosis. MPO stain was done on all cases of acute leukaemias and (20 cases) out of these showed positivity favouring a diagnosis of AML. PAS stain was done on all cases, (7 cases) of which showed block positivity favouring a diagnosis of ALL.

KEY WORDS: AM L, Lymphoid Leukaemia, M yeloid Leukaemia, Phenotypic Acute Leukaemia, Cytogenetic study.

Address for correspondence: Dr. S. Praveena, Assistant professor, Pathology Department, Dr. Patnam Mahender reddy institute of medical sciences, Hyderabad, Telangana, India.

E-M ail: praveena.bhushan@gmail.com

\begin{tabular}{|c|c|c|}
\hline \multicolumn{3}{|c|}{ Online Access and Article Informtaion } \\
\hline \multirow{2}{*}{ 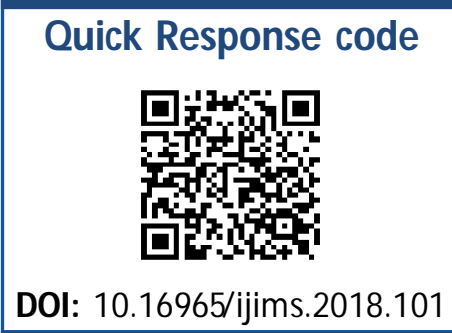 } & \multicolumn{2}{|c|}{$\begin{array}{l}\text { International Journal of Integrative Medical Sciences } \\
\text { www.imedsciences.com }\end{array}$} \\
\hline & $\begin{array}{l}\text { Received: 03-01-2018 } \\
\text { Reviewed: 04-01-2018 }\end{array}$ & $\begin{array}{l}\text { Accepted: 02-02-2018 } \\
\text { Published: 28-02-2018 }\end{array}$ \\
\hline Source of Funding: Self & \multicolumn{2}{|c|}{ Conflicts of interest: None } \\
\hline
\end{tabular}

\section{BACKGROUND}

Leukemia or leukaemia is a type of cancer of the blood or bone marrow characterized by an abnormal increase of immature white blood cells called blasts [1]. In 2000, all around the world approximately 256,000 children and adults form of leukemia, and 209,000 were died [2], 90\% of all leukemias are diagnosed in adults [3]. Leukemias are classified into two broad groups, myeloid and lymphoid, based on the origin of the leukemic stem cell clone. If myelocytic cells or other cells derived from the CFU-GEMM
(Colony forming unit-Granulocytic, Erythrocytic, M onocytic, M egakaryocytic) stem cell predominate, the disease is called myelogenous leukemia. If the lymphoid cells predominate, the disease is termed lymphocytic leukemia. AM L accounts for less than $15 \%$ of cases of leukemia in children below 10years, $25-30 \%$ between 10-15 years and in adults, it accounts for 80$90 \%$ of cases of acute leukemias [4]. ALL constitutes over $80 \%$ of childhood cases and comprises of $12 \%$ of all leukemias [5]. These lymphoid and myeloid leukemias are associated 
with varied systemic involvement such as anemia, splenomegaly, generalized lymphadenopathy and petechial haemorrhagic spots.

For this reason, the clinician also requires the basic peripheral blood smear study as a preliminary examination to differentiate the various diseases that overlap the symp tomatology of acute leukemia clinically. With this background we examined bone marrow and clinical manifestations for rule out the acute leukaemias in Telangana population.

\section{MATERIALS AND METHODS}

The study was done with 36 cases from August 2010 to September 2012. Peripheral blood and bone marrow aspirate samples received at the Department of Pathology, Kakatiya Medical College, and Warangal were studied in collaboration with Life Line Diagnostics, Hyderabad. Bone marrow aspirate and peripheral blood smear samples from patients of all age groups. Present with abnormal haematological findings suggestive of leukaemia, presenting with hepatosplenomegaly \&lymphadenopathy, investigated for pyrexia of unknown origin, complaining of bone pain were included in the study.

Table 1: Showing the AGE distribution of cases.

\begin{tabular}{|c|c|c|}
\hline 40yrs & $\mathbf{1 4}$ & $\mathbf{3 8 . 8 0} \%$ \\
\hline $\mathbf{1 0 - 1 9}$ yrs & 4 & $11.10 \%$ \\
\hline $\mathbf{2 0 - 2 9 y r s}$ & 3 & $8.30 \%$ \\
\hline $\mathbf{3 0 - 3 9 y r s}$ & 3 & $8.30 \%$ \\
\hline $\mathbf{4 0 - 4 9 y r s}$ & 9 & $25.00 \%$ \\
\hline $\mathbf{5 0 - 5 9 y r s}$ & 2 & $5.50 \%$ \\
\hline $\mathbf{6 0 - 6 9 y r s}$ & 1 & $2.77 \%$ \\
\hline $\mathbf{7 0 - 7 9 y r s}$ & 0 & $0.00 \%$ \\
\hline T0TAL & 36 & $\mathbf{1 0 0} \%$ \\
\hline
\end{tabular}

Table 2: Showing the GENDER distribution.

\begin{tabular}{|c|c|c|}
\hline Gender & $\begin{array}{c}\text { Number of } \\
\text { cases }\end{array}$ & percentage \\
\hline Male & 23 & $63.80 \%$ \\
\hline Female & 13 & $36.20 \%$ \\
\hline Total & 36 & $100.00 \%$ \\
\hline
\end{tabular}

Table 3: Showing the age distribution of acute leukaemias.

\begin{tabular}{|c|c|c|c|}
\hline Acute leukaemias & <18yrs & >18yrs & Total \\
\hline AML & 4 & 16 & 20 \\
\hline ALL & 13 & 2 & 15 \\
\hline $\begin{array}{c}\text { Mixed lineage Acute } \\
\text { leukaemia }\end{array}$ & 1 & 0 & 1 \\
\hline
\end{tabular}

Int J Intg M ed Sci 2018;5(2):571-76. ISSN 2394 - 4137
Patients who drop out of the study before complete work-up, due to death or discharge against advice have been excluded from the study. The relevant clinical history was obtained in each case, routine blood counts performed and peripheral smears studied in detail. About $0.5-1 \mathrm{ml}$ of bone marrow sample was collected from each case in EDTA and heparinized tubes. Smears from EDTA samples were stained with standard Romanowsky stain (Leishman stain) and studied for morphology of cells.

Table 4: Showing the clinical manifestations of the study population.

\begin{tabular}{|l|c|c|}
\hline Clinical Manifestations & $\begin{array}{c}\text { Number of } \\
\text { cases }\end{array}$ & Percentage \\
\hline Easy fatigability & 3 & $16.70 \%$ \\
\hline Fever & 11 & $61.10 \%$ \\
\hline Hepatomegaly & 2 & $11.10 \%$ \\
\hline Splenomegaly & 7 & $38.80 \%$ \\
\hline Weakness & 2 & $11.10 \%$ \\
\hline Pallor & 1 & $5.60 \%$ \\
\hline Bleeding manifestations & 1 & $5.60 \%$ \\
\hline Lymphadenopathy & 5 & $27.80 \%$ \\
\hline Weight loss & 1 & $5.50 \%$ \\
\hline Cough & 1 & $5.60 \%$ \\
\hline Loss of appetite & 2 & $11.10 \%$ \\
\hline
\end{tabular}

Graph 4: Clinical manifestations of the study population.

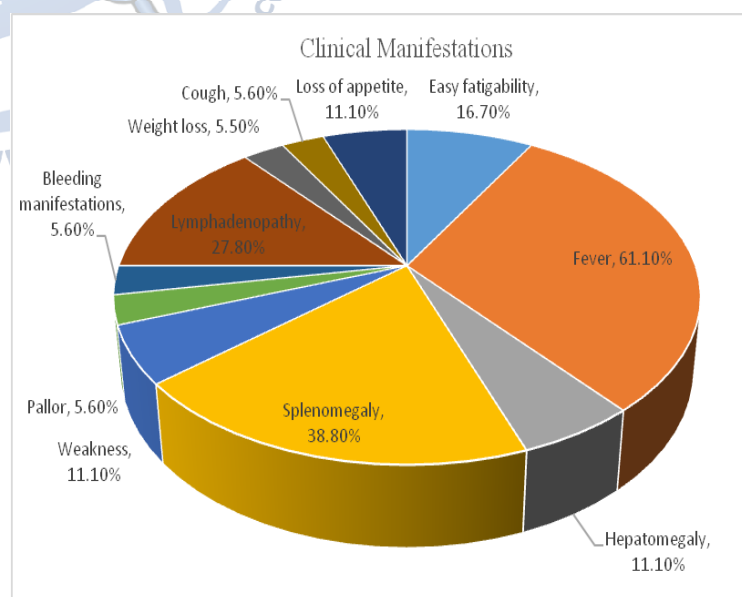

Table 5: Diagnosis on peripheral blood smear examination.

\begin{tabular}{|c|c|c|c|c|}
\hline \multirow{2}{*}{ Final Diagnosis } & \multicolumn{3}{|c|}{ Peripheral smear report } & \multirow{2}{*}{ Total } \\
\cline { 2 - 4 } & $\begin{array}{c}\text { Acute } \\
\text { leukaemia }\end{array}$ & AL & AML & \\
\hline $\begin{array}{c}\text { Mixed lineage Acute } \\
\text { leukaemia }\end{array}$ & 1 & 0 & 0 & 1 \\
\hline ALL & 10 & 5 & 0 & 15 \\
\hline AML & 7 & 0 & 13 & 20 \\
\hline Total & 18 & $\mathbf{5}$ & 13 & 36 \\
\hline
\end{tabular}


Table 6: Diagnosis on bone marrow examination.

\begin{tabular}{|c|c|c|c|c|}
\hline \multirow{2}{*}{ Final diagnosis } & \multicolumn{2}{|c|}{ Bone marrow examination } & \multirow{2}{*}{ Total } \\
\cline { 2 - 5 } & $\begin{array}{c}\text { Acute } \\
\text { leukaemias }\end{array}$ & AL & AML & \\
\hline $\begin{array}{c}\text { Mixed lineage acute } \\
\text { leukaemia }\end{array}$ & 1 & 0 & 0 & 1 \\
\hline AL & 4 & 11 & 0 & 15 \\
\hline AML & 1 & 0 & 19 & 20 \\
\hline Total & 6 & 11 & 19 & 36 \\
\hline
\end{tabular}

\section{DISCUSSION}

The highest number of cases were in the age group <10yrs (14cases) which constituted $38.8 \%$ cases followed by the age group 40-49yrs of age ( 9 cases) which constituted $25 \%$ cases. In that 23 cases $(63.8 \%)$ of cases were males and 13 cases $(36.2 \%)$ were females, the male female ratio being1.76:1. Kaushal et al [6] in their study reported male: female ratio 1.08:1 and Charrin et al [7] reported 1.5:1 in their study.

In this study out of 20 cases of AM L 16 cases were adults (80\%) and 4 cases were children $20 \% .20$ cases of AM L included 12 males and 8 females. Out of 15 cases of ALL 2 cases were adults $(13.3 \%)$ and 13 cases were children (86.67\%). 15 cases of ALL included 11 males and 4 females.

1 case of mixed lineage acute leukaemia was a female. This correlated with findings of Ghosh et al [8] had $76 \%$ adult AML \& $24 \%$ childhood ALL. Out of 15 cases of ALL 13 cases (86.7\%) were children and 2 cases were adults (13.3\%).

Different types of leukaemias have different clinical presentations. In the present study most common clinical presentation of patients was fever followed by splenomegaly. Lymphadenopathy was the clinical presentation in children with ALL and also Koushal et al [6] found splenomegaly as the commonest presentation (81\%) followed by hepatomegaly (69\%) and fever (61\%). But Ghosh et al [8], pallor and weakness were the commonest clinical findings (82\%) followed by lymphadenopathy (36.2\%). The majority of cases were AML (20 cases) followed by ALL ( 15 cases) and 1 case of mixed lineage acute leukaemia in this study. Vinsheeth et al [9] 48 in their study found CML as the commonest leukaemia (110 cases) followed by AML (18) and ALL (10). This study is almost in concordance with other studies except for higher no of $A M L$ cases which could be due to population bias. In the present study out of 20 cases of AML, AML-M 2 with 4 cases was the commonest followed by $\mathrm{M} 3$ with 3 cases. This is in league with the study done by Ghosh et al [8] with AM L-M 2 being the commonest subtype in adults (32\%) and also in children (42\%).

Fig. 1: Peripheral smear, Leishman stain X 1000 ALL-L1Blasts of homogenous morphology showing cleaved nuclei.

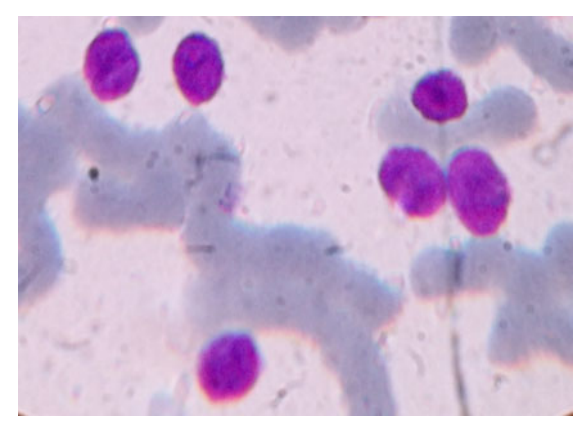

Fig. 2: peripheral smear, Leishman stain X 1000 ALL-L2Blasts of heterogenous morphology showing condensed chromatin.

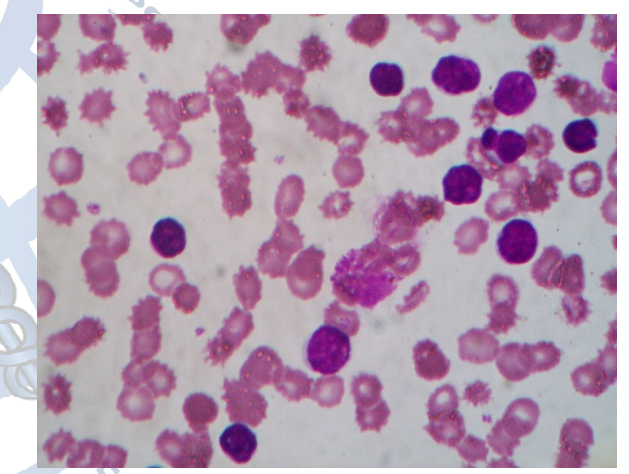

Fig. 3: Peripheral smear leishman stain X 1000 AM L-M 3, Promyel ocytes with granules enveloping the nucleus.

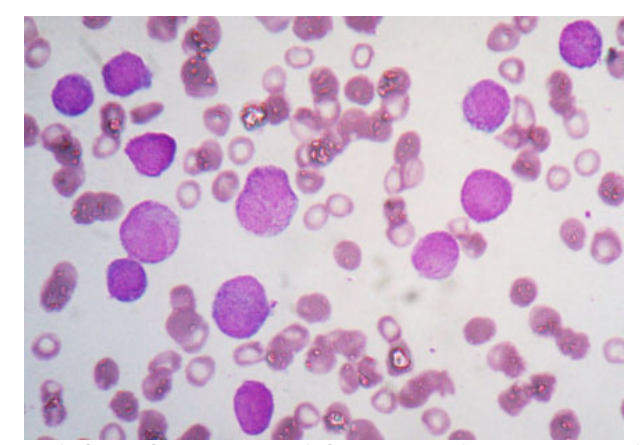

Fig. 4: Peripheral smear, Leishman stain X1000 a single promyelocyte with granules enveloping the nucleus.

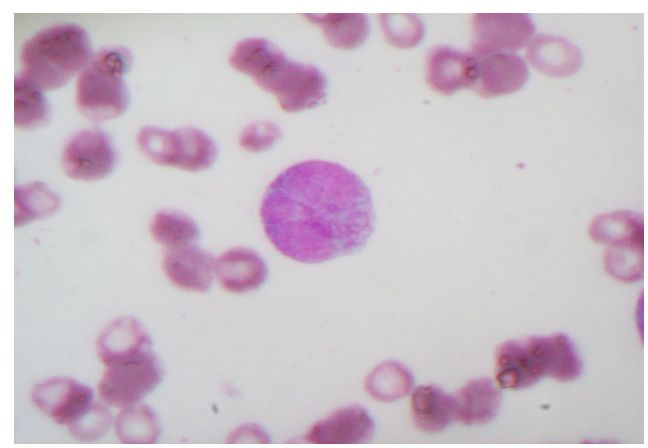


Fig. 5: peripheral smear Myeloperoxidase stain promyelocytes showing intense positivity with brownish granules.

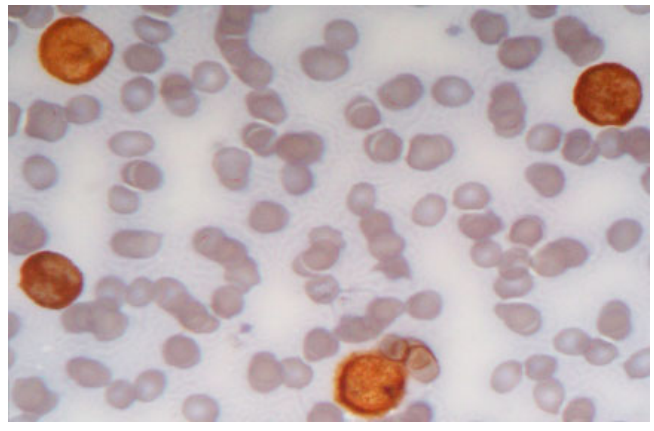

Fig. 6: Peripheral smear, Leishman stain X1000 Monoblasts with pale blue cytoplasm and open nuclear chromatin.

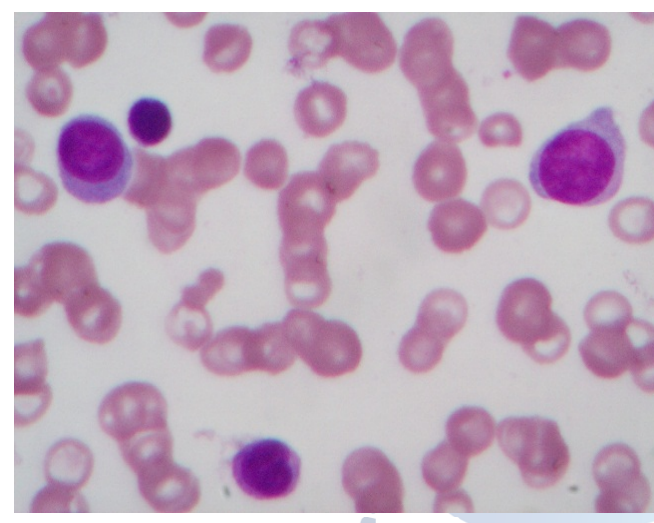

Peripheral smear was done in all cases (36 cases) 13 out of 20 (65\%) cases of AML were diagnosed on peripheral blood smear examination, though accurate sub typing was not possible in some of these cases. The remaining 7 cases were just identified as acute leukaemias, as it was difficult to subtype these as either AM L-M $0 \& A L L-L 1$ the morphology of the 2 being similar. 5 out of 15 cases (33.3\%) cases of ALL were diagnosed on peripheral smear examination but accurate sub typing was not possible in some of these cases. The remaining 10 cases were just identified as acute leukaemias, as it was difficult to subtype these as either AM L-M $0 \&$ ALL-L1 the morphology of the 2 being similar. 1 case of mixed lineage was just identified as acute leukaemia. Among the AM $L$ cases sub typed on peripheral blood smear examination were AM L-M 2 (1 cases), AM L-M 3 (3 cases) \& among ALL cases were ALL-L1 (1case) and ALL-I2 (1case). M PO and PAS stain was done on all 36 cases of acute leukaemias and $20(55.5 \%)$ out of these showed positivity favoring the diagnosis of $A M L$, and 7(19.5\%) of these showed positivity for PAS favoring a diagnosis of ALL.

Int J Intg M ed Sci 2018;5(2):571-76. ISSN 2394 - 4137
Fig. 7: Bone marrow Giemsa stain X 1000 ALL-L1-Blasts of homogenous morphology showing cleaved nuclei.

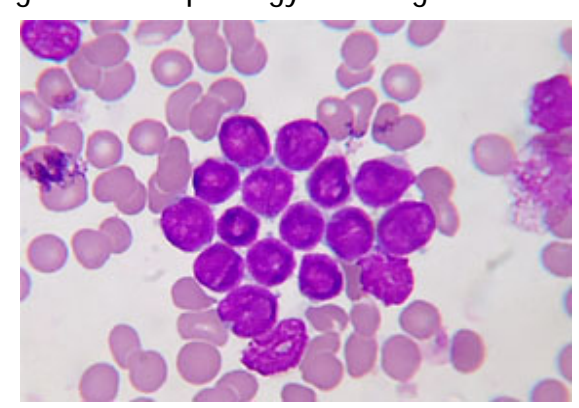

Fig. 8: Bone marrow Giemsa stain X 1000 AM LM 0/ ALLL1-Blasts of homogenous morphology with indistinct Nucleoli.

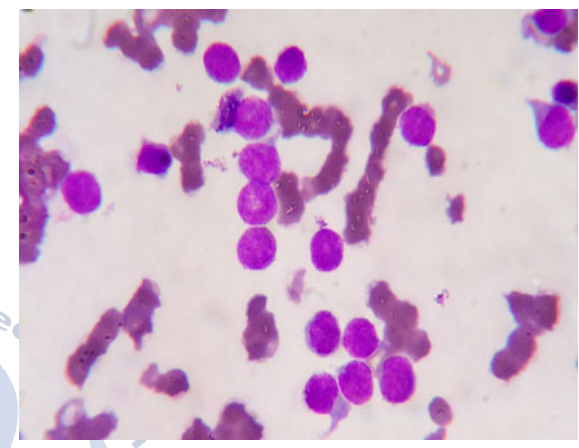

Fig. 9: Bone marrow smear M PO stain X1000 Blasts show intense cytoplasmic positivity with brownish granules

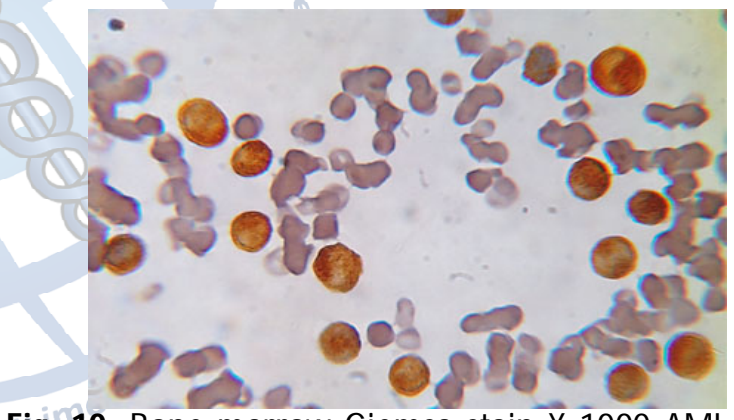

Fig. 10: Bone marrow Giemsa stain X 1000 AML-M 1, Blasts showing prominent 3-4 nucleoli.

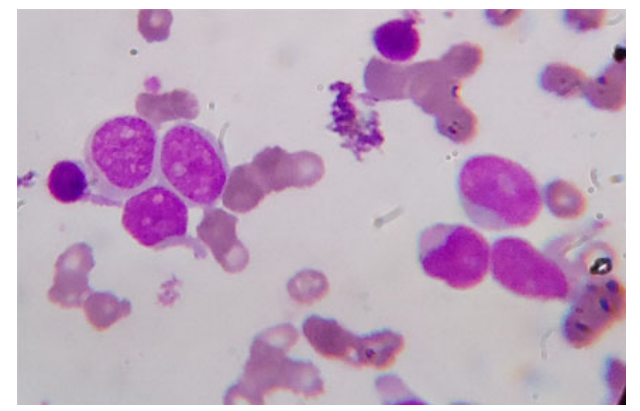

Fig. 11: Bone marrow Giemsa stain X 1000 AM L-M 2, Blasts showing prominent Auer rods.

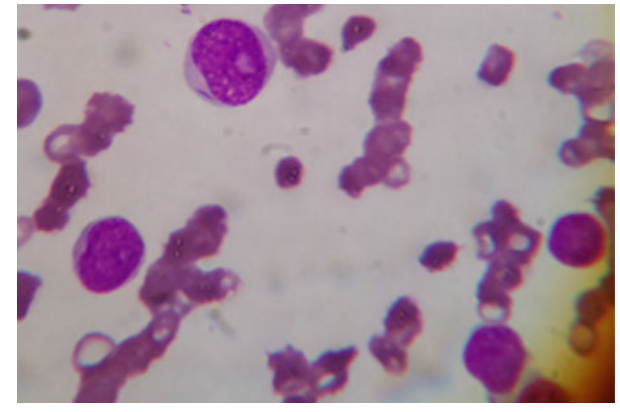


Fig. 12: Bone marrow, Giemsa stain X 1000 AM L-M 4, Blasts showing cytoplasmic vacuoles.

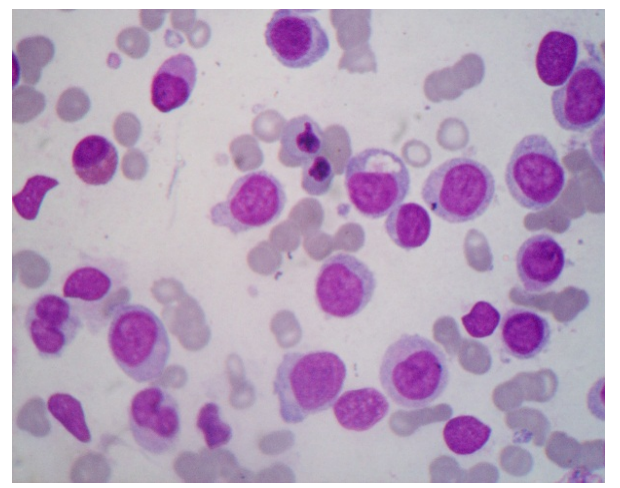

Fig. 13: Bone Marrow Giemsa stain X 1000 AM L-M 5, Monoblasts showing pale blue cytoplasm with open Chromatin and prominent nucleoli.

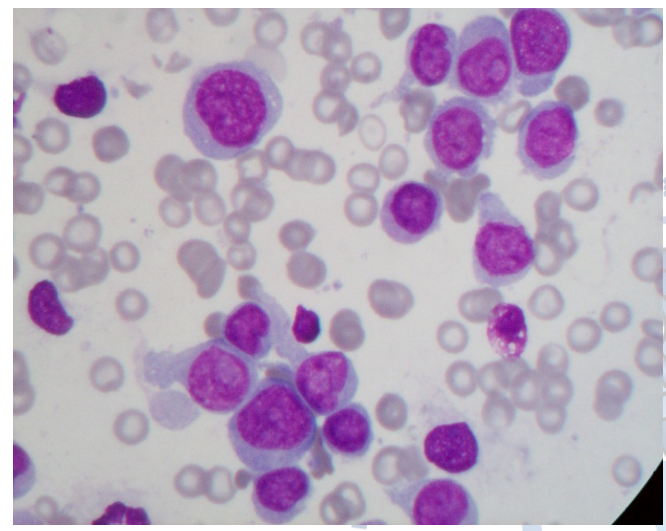

Bone marrow examination was done in all 36 cases. 19 out of 20 cases (95\%) of AML were diagnosed on bone marrow examination, though accurate sub typing is not possible in some of these cases. Out of 19 cases of AML that were diagnosed the following subtypes were seen:

- 2 cases of AM L-M 1

- 5 cases of AML-M 2

- 3 case of AM L-M 3

- 2 cases of AM LM -5

- 1 case of AM L-5a

11 out of 15 cases (73.3\%) of ALL were diagnosed on BME but accurate sub typing is not possible in some of these cases. Among ALL 4 cases of ALL-L1, 2 cases of ALL-L2 were typed based on their morphology. Further sub typing was not possible on morphology alone, in 4 cases of $A M L$ $\& 5$ cases of ALL. 1 case of mixed lineage acute leukaemia was diagnosed as just acute leukaemia. Similarly found in M rozek Ket al study [10].

From this study by using morphology, cytochemistry findings accurate diagnosis was arrived in all 36 cases. This is help for the treatment of leukaemias. We can also monitor the therapeutic response and cytogenetic response of leukaemias. Hence we conclude that in identifying the lineage specificity of various types of leukaemias and helps on arriving at a final diagnosis especially in cases with ambiguous morphology on peripheral blood smear and bone marrow examination.

\section{CONCLUSION}

Leukemia or leukaemia is a type of cancer of the blood or bone marrow, the incidence of various types of leukaemias varies considerably in different age groups, racial and ethnic differences too. There may be population bias, which leads to variation in the prevalence of different types of leukaemias. Out of 36 blood and bone marrow samples studied, a final diagnosis was given after correlating morphology, cytochemistry. This is helping for classification and treatment of leukaemias. Hence we conclude that in identifying the lineage specificity of various types of leukaemias and helps on arriving at a final diagnosis especially in cases with ambiguous morphology on peripheral blood smear and bone marrow examination.

\section{REFERENCES}

[1]. Leukemia, in Mosby's Medical, Nursing \& Allied Health Dictionary, Fourth Edition, M osby-YearBook, Inc., 1994, p. 903

[2]. Mathers, Colin D, Cynthia Boschi Pinto, Alan D Lopez and Christopher JL M urray (2001). "Cancer incidence, mortality and survival by site for 14 regions of the world". Global Programme on Evidence for Health Policy Discussion Paper No. 13 (World Health Organization).

[3]. SEER Stat Fact Sheets: Leukemia. National Cancer Institute. 2011. Approximately $10.8 \%$ were diagnosed under age 20.

[4]. Greer John P, Baer Maria. R, Kinney Marsha. C, Wintrobe's Clinical Hematology. 10th edition, Williams and Wilkins, volume 2, 1999, 2273.

[5]. Redaelli A, Laskin BL, Stephens JM, Botteman $\mathrm{MF}$, Pashos CL. A systematic literature review of the clinical and epidemiological burden of acute lymphoblastic leukaemia (ALL). Eur J Cancer Care (Engl). 2005;14(1):53-62.

[6]. Kaushal, S., Sidhu, S.S., Anand, N., Patnaik, V.V.G., Singla, Rajan K. A study of chromosomal morphology in leukaemias" journal of Anatomy society India. 2001:50(20);112-8.

[7]. Charrin c. Cytogenetic abnormalities in acute lymphoblastic leukaemias. Coloborative study of the group $m$ Francais de cytogenetique, haematologique. Blood. 1996:87(8);3135-42. 
[8]. Ghosh S, Shinde SC, Kumaran GS, Sapre RS, Dhond $S R$, Badrinath $Y$, et.al. Haematologic and immunophenotypic profile of acute myeloid leukemia: an experience of Tata M emorial Hospital. Indian J Cancer. 2003;40(2):71-6.

[9]. Vinsheth FJ, Sheth JJ, Patel Al, Shah AD, Verhest A. Usefulness of cytogenetics in leukemias. Indian J Cancer. 2002;39(4):139-42.
[10].Mrózek K, Heinonen K, Bloomfield CD. Clinical importance of cytogenetics in acute myeloid leukaemia. Best Pract Res Clin Haematol. 2001;14(1):19-47.

How to cite this article: S. Praveena, K. Durga. ACUTE LEUKAEM IAS ON BONE M ARROW EXAM INATION AND CLINICAL M ANIFESTATIONS IN THE TELANGANA POPULATION. Int J Intg M ed Sci 2018;5(2):571576. DOl: $10.16965 / \mathrm{ijims} .2018 .101$

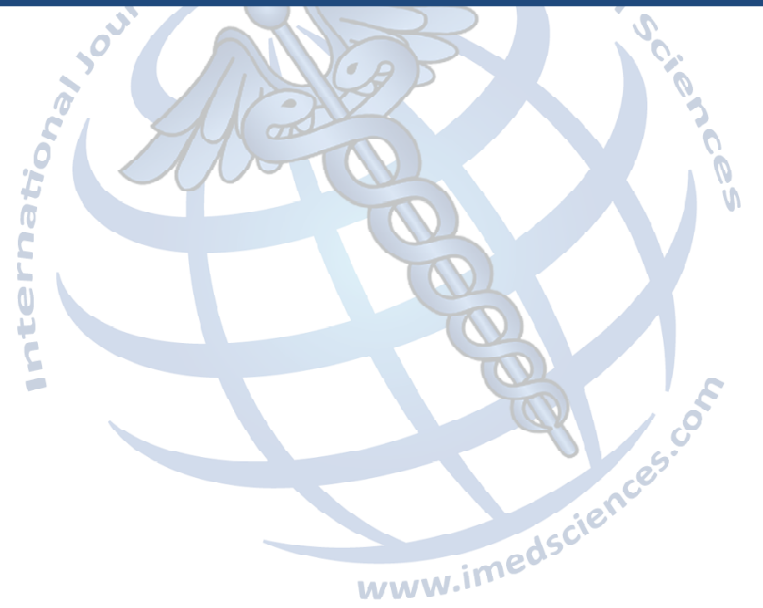

